\title{
EurJOC
}

European Journal of Organic Chemistry

\section{Phemistry Europe}

European Chemical Societies Publishing

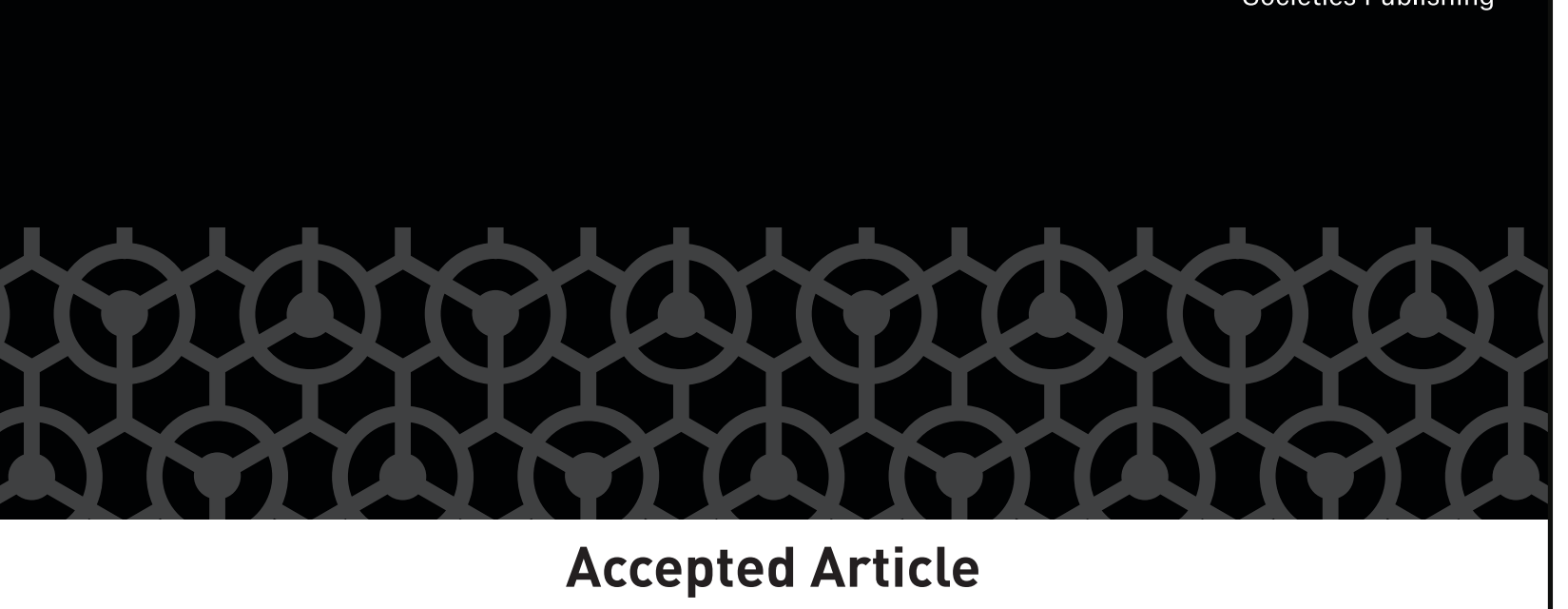

Title: Multicomponent Synthesis of Sulfones and Sulfides from

Triarylbismuthines and Sodium Metabisulfite in Deep Eutectic

Solvents

Authors: Beatriz Saavedra, Xavier Marset, Gabriela Guillena, and Diego J. Ramón

This manuscript has been accepted after peer review and appears as an Accepted Article online prior to editing, proofing, and formal publication of the final Version of Record (VoR). This work is currently citable by using the Digital Object Identifier (DOI) given below. The VoR will be published online in Early View as soon as possible and may be different to this Accepted Article as a result of editing. Readers should obtain the VoR from the journal website shown below when it is published to ensure accuracy of information. The authors are responsible for the content of this Accepted Article.

To be cited as: Eur. J. Org. Chem. 10.1002/ejoc.202000425

Link to VoR: https://doi.org/10.1002/ejoc.202000425 


\title{
Multicomponent Synthesis of Sulfones and Sulfides from Triarylbismuthines and Sodium Metabisulfite in Deep Eutectic Solvents
}

\author{
Beatriz Saavedra, ${ }^{[a]}$ Xavier Marset, ${ }^{[a]}$ Gabriela Guillena, ${ }^{*[a]}$ Diego J. Ramón ${ }^{*[a]}$ \\ [a] Beatriz Saavedra, Xavier Marset, Prof. Dr. Gabriela Guillena and Prof. Dr. Diego J. Ramón \\ Departamento de Química Orgánica and Instituto de Síntesis Orgánica (ISO), Facultad de Ciencias Universidad de Alicante, Apdo. 99,03080 Alicante, \\ Spain \\ Email: gabriela.guillena@ua.es; https://personal.ua.es/es/gabriela-guillena/ \\ djramon@ua.es; https://personal.ua.es/en/djramon/research-group-of-diego-j-ramon.html \\ Supporting information for this article is given via a link at the end of the document.
}

\begin{abstract}
This study describes a novel and catalyst-free methodology for the multicomponent synthesis of a broad range of sulfones, disulfides and sulfides from non-toxic triarylbismuthines $\left(\mathrm{Ar}_{3} \mathrm{Bi}\right)$ and sodium metabisulfite $\left(\mathrm{Na}_{2} \mathrm{~S}_{2} \mathrm{O}_{5}\right)$ in deep eutectic solvents (DESs). The fine tuning of the DESs properties allowed the solubility of all reagents, enhancing their reactivity, as well as, the recyclability of the reaction medium for at least 5 consecutive cycles. Thus, this versatile strategy uses non-toxic reagents without the need of metal catalysts in a sustainable solvent, being an interesting alternative to traditional hazardous protocols.
\end{abstract}

\section{Introduction}

Organosulfur compounds play an essential role in organic chemistry for the development of novel chemical structures. Sulfones are important structural motifs that serve as versatile intermediates in organic synthesis ${ }^{[1]}$ and are used in classic organic transformations such as the Ramberg-Bäcklund rearrangement ${ }^{[2]}$ and the Julia olefination. ${ }^{[3]}$ In addition, sulfonylcontaining compounds feature in a broad range of bioactive molecules, and are common motifs in pharmaceuticals and agrochemicals (Figure 1). ${ }^{[4]}$
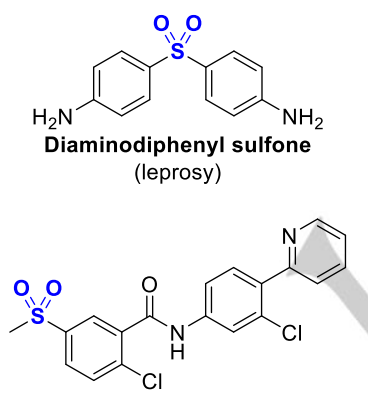

Vismodegib (anticancer)

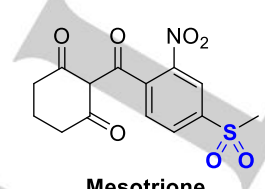

Mesotrione (herbicide)

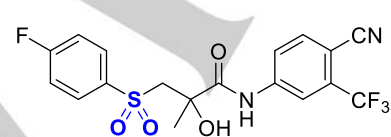

Bicalutamide (prostate cancer)
Figure 1. Representative biologically active sulfone motifs.

As a result of their widespread use, efficient and robust approaches toward the synthesis of sulfones are highly demanded. The common approaches to prepare sulfones include oxidation of the corresponding sulfides, that usually requires thiol substrates and oxidative conditions. ${ }^{[5]}$ The use of this methodology has some restrictions due to the unpleasant odor of thiols, their relatively limited commercial availability, as well as, the incompatibility with the presence of oxidationsensitive functional groups in the starting materials. Another widely used strategy to synthesize sulfones is the transitionmetal catalyzed sulfonylation with sulfonyl halides or sodium sulfinates, ${ }^{[6]}$ including sulfonyl-type radical additions. ${ }^{[7]}$ All these protocols are based on organic sulfur-containing reagents, which are often difficult to prepare and therefore of limited availability.

A more versatile approach is the direct introduction of $\mathrm{SO}_{2}$ (g) in a three-component process. ${ }^{[8]}$ However, this methodology has important limitations, such as toxicity and the issues associated with handling gaseous sulfur dioxide. An alternative, that avoids these drawbacks, is the use of $\mathrm{SO}_{2}$-surrogates such as $\mathrm{DABSO}^{[9]}$ or inorganic sulfites. ${ }^{[10]}$ Notwithstanding, there are several aspects to improve these methodologies, such as the use of specialized and expensive ligands and catalysts, generally in high loadings. Also, other limitations are the requirement for stoichiometric phase-transfer additives, airsensitive reagents, poor solubility of the inorganic sulfites in organic media and the use of volatile and harmful solvents. As a consequence, the development of new methodologies to access diversely functionalized sulfur-containing molecules remains in demand.

The use of neoteric solvents could introduce new opportunities in order to develop new reactions and approaches. Deep eutectic solvents (DESs) are a new class of solvents, which are generally composed by two or three cheap and safe components, capable of associating with each other, through mainly hydrogen bond interactions, to form a eutectic mixture. DESs are important alternatives to volatile organic solvents due to their unique properties, such as easy synthesis, low cost, low volatility, high dissolution power, high biodegradability and feasibility of structural design. ${ }^{[11]}$ A glaring example of this, is the eco-friendly formation of sulfides and sulfones in choline chloride-based low transition temperature mixtures by a direct nucleophilic addition of thiolate and sulfinate ions to in situderived nitrosoalkenes from a-clorooximes, under air and mild conditions. ${ }^{[12]}$

In this study and for the first time, the development of a novel multicomponent methodology of synthesis of sulfurcontaining compounds (sulfones, disulfides and sulfides) is described, taking into account all current environmental requirements. ${ }^{[13]}$ Achieved results are even superior to those 
reported using non-environmentally friendly protocols. The protocol is based on the generation of aryl sulfinates ${ }^{[14]}$ from triarylbismuthines reagents $\left(\mathrm{Ar}_{3} \mathrm{Bi}\right)$ and $\mathrm{Na}_{2} \mathrm{~S}_{2} \mathrm{O}_{5}$ as a non-toxic sulfonyl source. DESs were used as a novel medium for sulfone synthesis, taking the advantage of the high solubility of $\mathrm{SO}_{2}(\mathrm{~g})$ in this type of solvents. ${ }^{[15]}$ The use of DESs enhanced the reactivity, highlighting the great importance of the medium, and leading to new reactivities in this type of sustainable solvents. Also, triarylbismuthines are particularly attractive since they are non-toxic, air and moisture stable and they can also transfer their three aryl moieties, increasing the atom economy of the process. ${ }^{[16]}$

\section{Results and Discussion}

The study started by optimizing the reaction conditions using triphenylbismuthine (1a), $\mathrm{Na}_{2} \mathrm{~S}_{2} \mathrm{O}_{5}$ (2) and benzyl bromide (3a) as the model reaction (Table 1). The reaction in typical organic solvents failed or gave a modest result (entries 1-5). When protic solvents were used, only in the case of methanol, the result was promising (entries 6-8). Then, different eutectic mixtures were tested (entries 9-11), obtaining a quantitative yield without catalyst and using the non-toxic mixture acetylcholine chloride:acetamide ${ }^{[17]}$ (1:2; entry 11). These results highlighted the ability of DESs to modulate reactivity properties fitting to requirements of the reaction, such as activation role or solubility of inorganic salts $\left(\mathrm{Na}_{2} \mathrm{~S}_{2} \mathrm{O}_{5}\right)$ and solubility of in situ generated $\mathrm{SO}_{2}$. Also, the rest of the organic and intermediates formed by the reaction, between triphenylbismuthine and the $\mathrm{SO}_{2-}$ surrogate are entirely dissolved in the DES mixture.

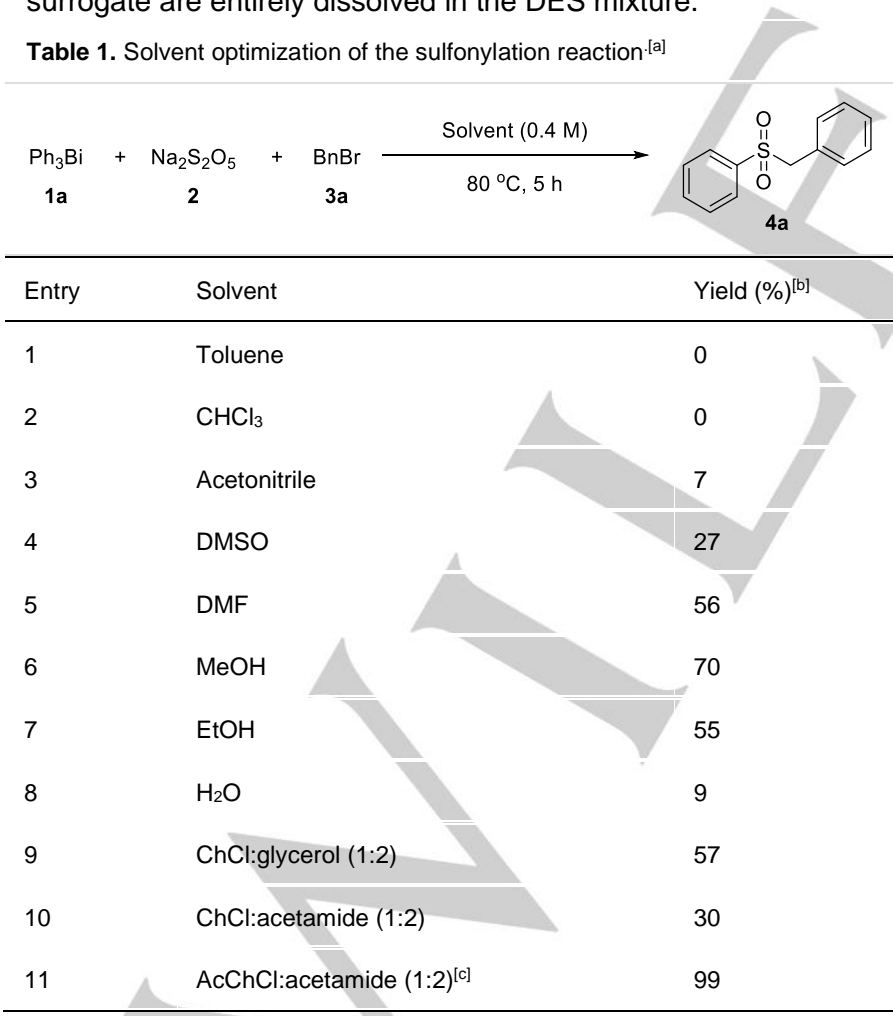

[a] Reaction conditions: $\mathrm{Ph}_{3} \mathrm{Bi}(0.1 \mathrm{mmol}), \mathrm{Na}_{2} \mathrm{~S}_{2} \mathrm{O}_{5}(0.66 \mathrm{mmol})$ and $\mathrm{BnBr}(0.60$ mmol) in $0.75 \mathrm{~mL}$ of solvent were stirred at $80^{\circ} \mathrm{C}$ for $5 \mathrm{~h}$. ${ }^{[b]}$ Yield determined by $\mathrm{GC}$ using tridecane as an internal standard. ${ }^{[c]} \mathrm{AcChCl}$ (acetylcholine chloride).
Additionally, it is worth mentioning that the choice of an appropriate DES was proven to be crucial for the reaction, thus leading to opportunities to find new reactivities and methodologies with less ecological footprint.

Once the optimal conditions were determined (entry 11 in Table 1), the scope of this sustainable multicomponent transformation was evaluated. First, different electrophiles were used (Table 2). The reaction proceeded with different alkyl halides, as electrophiles, (entries 1-3).2-Chlorobenzo[d]thiazole afforded product $\mathbf{4 d}$ in a good yield (entry 4 ). Less conventional electrophiles such as diaryliodonium salts could be employed (entry 5). Also, electron poor alkenes could react as electrophiles in the sulfonylation reaction (entries 6-7). It is worthy to note that the reaction conditions tolerated a wide number of functionalities, including carboxylic acids.

Table 2. Scope of the electrophiles in the sulfonylation reaction ${ }^{\text {[a] }}$

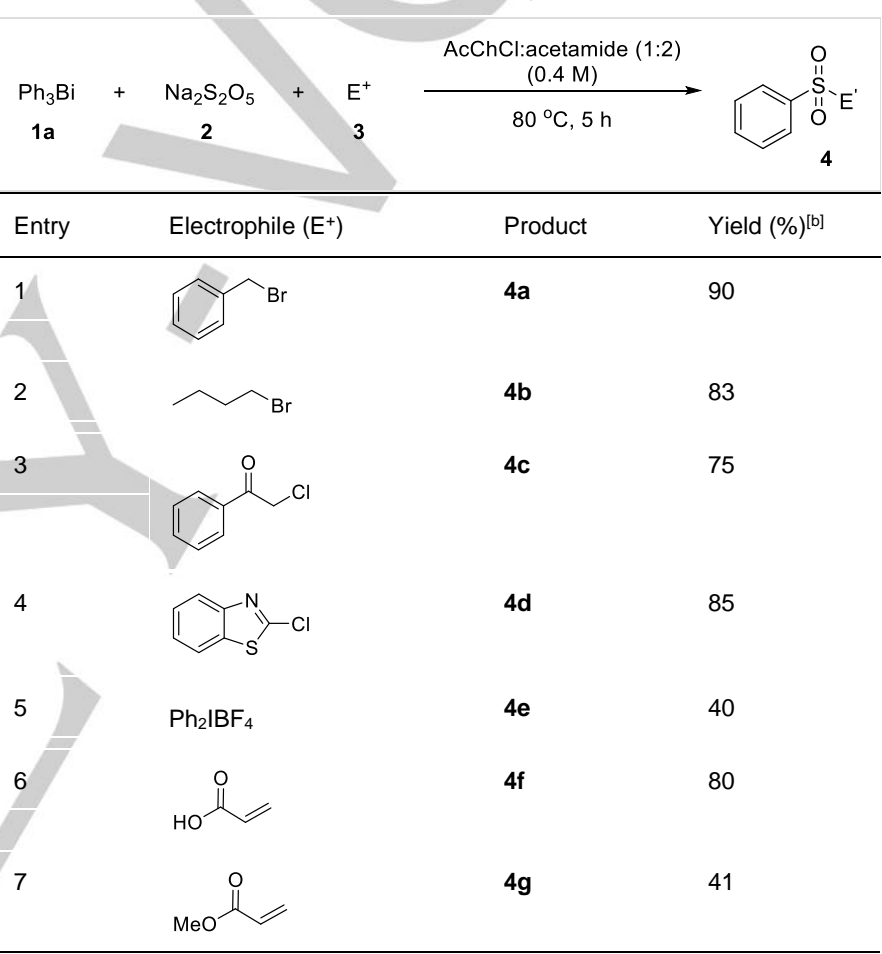

[a] Reaction conditions: $\mathrm{Ph}_{3} \mathrm{Bi}(0.2 \mathrm{mmol}), \mathrm{Na}_{2} \mathrm{~S}_{2} \mathrm{O}_{5}(1.32 \mathrm{mmol})$ and $\mathrm{E}^{+}(1.2$ $\mathrm{mmol}$ ) in $1.5 \mathrm{~mL}$ of solvent were stirred at $80^{\circ} \mathrm{C}$ for $5 \mathrm{~h}$. [b] Yield of compounds isolated by column chromatography and calculated assuming that all three aryl moieties are transferred.

Next, different triarylbismuthines were evaluated (Table 3). Slightly better yields were obtained with neutral triarylbismuthines (entries 1-2), but, in general, the electronic nature of the aromatic ring of triarylbismuthines does not seem to have any effects on the scope of electrophiles (entries 3-8).

In the possible mechanism pathway, an aryl sulfinate salt is postulated to be formed after the first reaction step. To investigate the versatility of this process, including the tolerance of organometallic reagent and solvent, we tested the addition of iodine to the reaction mixture. ${ }^{[18]}$ In this way, a radical process could also take place in this new reaction medium, affording the corresponding disulfide in the absence of any other reagent (Table 4). 
Table 3. Scope of the triarylbismuthines in the sulfonylation reaction ${ }^{\text {[a] }}$

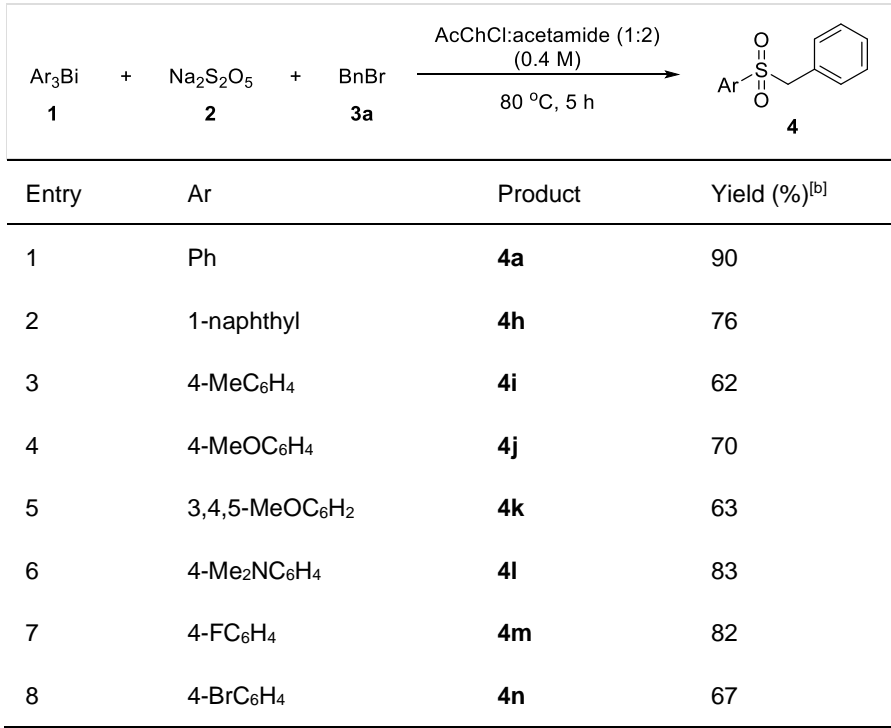

[a] Reaction conditions: $\mathrm{Ar}_{3} \mathrm{Bi}(0.2 \mathrm{mmol}), \mathrm{Na}_{2} \mathrm{~S}_{2} \mathrm{O}_{5}$ (1.32 mmol) and $\mathrm{BnBr}(1.2$ $\mathrm{mmol}$ ) in $1.5 \mathrm{~mL}$ of solvent were stirred at $80^{\circ} \mathrm{C}$ for $5 \mathrm{~h}$. ${ }^{[b]}$ Yield of compounds isolated by column chromatography and calculated assuming that all three aryl moieties are transferred.

In this case, the electronic nature of the aromatic ring had a notable impact in the reaction. In general, good results were obtained with triarylbismuthines bearing neutral or electron withdrawing groups (entries 1-2 and 5-6). Nevertheless, a significant drop in the reaction yield was observed with electrondonor substituents, such as methyl or methoxy groups (entries 3-4).

Table 4. Scope of the aryl disulfides ${ }^{[a]}$

\begin{tabular}{|c|c|c|c|}
\hline $\begin{array}{c}\mathrm{Ar}_{3} \mathrm{Bi} \\
1\end{array}$ & $\begin{array}{l}\text { 1) } \mathrm{Na}_{2} \mathrm{~S}_{2} \mathrm{O}_{5}(2 \\
\text { 2) } \mathrm{I}_{2}(2.0 \text { equi } \\
\mathrm{AcChCl}:\end{array}$ & $\begin{array}{l}\text {.), } 80^{\circ} \mathrm{C}, 5 \mathrm{~h} \\
\mathrm{C}, 20 \mathrm{~min} \\
\text { de }(1: 2)\end{array}$ & $S_{1}$ \\
\hline Entry & $\mathrm{Ar}$ & Product & Yield $(\%)^{[b]}$ \\
\hline 1 & $\mathrm{Ph}$ & $5 a$ & 65 \\
\hline 2 & 1-naphtyl & $5 b$ & 51 \\
\hline 3 & 4- $\mathrm{MeC}_{6} \mathrm{H}_{4}$ & $5 c$ & 27 \\
\hline 4 & $4-\mathrm{MeOC}_{6} \mathrm{H}_{4}$ & $5 d$ & 36 \\
\hline 5 & $4-\mathrm{FC}_{6} \mathrm{H}_{4}$ & $5 e$ & 80 \\
\hline 6 & $4-\mathrm{BrC}_{6} \mathrm{H}_{4}$ & $5 f$ & 70 \\
\hline
\end{tabular}

[a] Reaction conditions: $\mathrm{Ph}_{3} \mathrm{Bi}(0.2 \mathrm{mmol}), \mathrm{Na}_{2} \mathrm{~S}_{2} \mathrm{O}_{5}(1.32 \mathrm{mmol})$ in $1.5 \mathrm{~mL}$ of solvent were stirred at $80{ }^{\circ} \mathrm{C}$ for $5 \mathrm{~h}$, then $\mathrm{I}_{2}$ was added and the mixture was stirred for $20 \mathrm{~min}$. ${ }^{[b]}$ Yield of compounds isolated by column chromatography. Yield calculated assuming that all three aryl moieties are transferred and two of them are in the final product.

Sulfinate salts have been employed as starting materials in the synthesis of different sulfides. In these cases, iodine was also added to the sulfinate allowing the synthesis of various sulfides via C-H functionalization. ${ }^{[19]}$ In view of those precedents, a three step process in a one-pot manner was proposed for the synthesis of various sulfides (formation of sulfinate salt, transformation to thiol derivative and reaction with nucleophile/radical scavenger). The obtained results are depicted in Table 5, showing moderate to good yields using phenol/anisole derivatives (entries 1-2), N,N-dimethylaniline (entry 3 ) or even indole as a nucleophile/radical scavenger (entry 4). If a nucleophilic functionalized alkene is added, the double bond reacts initially with the in situ formed radical thiol, being then the radical trapped by the hydroxyl functionality affording cyclic products $6 \mathrm{e}-\mathrm{g}$ (entries 5-7).

Table 5. Scope of the aryl sulfides [a]

\begin{tabular}{|c|c|c|c|c|}
\hline \multirow{3}{*}{$\begin{array}{c}\mathrm{Ph}_{3} \mathrm{Bi} \\
\mathbf{1 a} \\
\text { Entry }\end{array}$} & \multicolumn{3}{|c|}{$\begin{array}{l}\text { 1) } \mathrm{Na}_{2} \mathrm{~S}_{2} \mathrm{O}_{5}\left(2.2 \text { equiv.), } 80^{\circ} \mathrm{C}, 5 \mathrm{~h}\right. \\
\text { 2) } \mathrm{I}_{2}\left(2.0 \text { equiv.), } 80^{\circ} \mathrm{C}, 20 \mathrm{~min}\right. \\
\text { 3) } \mathrm{Nu}-\mathrm{H} \text { or radical scavenger }\left(2.0 \text { equiv.), } 80^{\circ} \mathrm{C}, 8 \mathrm{~h}\right.\end{array}$} & \multirow{2}{*}{$\mathrm{Nu}_{6}^{-\mathrm{S}_{-}}{ }^{\mathrm{Ph}}$} \\
\hline & & & & \\
\hline & $\mathrm{Nu}-\mathrm{H}$ or radical scavenger & Product & & $\begin{array}{l}\text { Yield } \\
(\%)^{[b]}\end{array}$ \\
\hline 1 & & & $6 a$ & 72 \\
\hline 2 & & & $6 b$ & 79 \\
\hline 3 & & & $6 c$ & 67 \\
\hline 4 & & & $6 \mathrm{~d}$ & 81 \\
\hline 5 & & & $6 e$ & 52 \\
\hline 6 & $\mathrm{HO}^{-}$ & & $6 f$ & 77 \\
\hline 7 & o & & $6 \mathrm{~g}$ & 73 \\
\hline
\end{tabular}

[a] Reaction conditions: $\mathrm{Ph}_{3} \mathrm{Bi}(0.2 \mathrm{mmol}), \mathrm{Na}_{2} \mathrm{~S}_{2} \mathrm{O}_{5}(1.32 \mathrm{mmol})$ in $1.5 \mathrm{~mL}$ of solvent were stirred at $80^{\circ} \mathrm{C}$ for $5 \mathrm{~h}$, then $\mathrm{I}_{2}$ was added and the mixture was stirred for $20 \mathrm{~min}$. Finally, $\mathrm{Nu}-\mathrm{H}$ or radical scavenger $(1.2 \mathrm{mmol})$ was added and the mixture was stirred for another $8 \mathrm{~h}$ at $80^{\circ} \mathrm{C}$. [b] Yield of compounds isolated by column chromatography and calculated assuming that all three aryl moieties are transferred.

Then, we decided to study the recyclability of the system, which is a crucial point for the sustainability of the process. Once the reaction was finished, the mixture was extracted with 2 MeTHF ${ }^{[20]}$ (a renewable volatile organic compound) to remove all organic compounds from DES, and the mixture of DES could be reused up to 5 consecutive cycles under the same reaction conditions, with only a slightly decrease in the yields (Figure 2).

Another important aspect to be controlled in a sustainable process is the waste materials. Thus, the amount of wasted bismuth compounds could be also controlled just by adjusting the $\mathrm{pH}$ of the aqueous work-up. When the model reaction (see Table 1, entry 11) was quenched with only water and the organic products were extracted with 2-MeTHF, the aqueous phase contained $0.1 \%$ of the initial bismuth (ICP-OES analysis). 
However, if the presence of bismuth impurities in the desired product are not allowed for some purposes, for instance in medicinal chemistry, $\mathrm{HCl} 2.0 \mathrm{M}$ can be added instead of water, with $99 \%$ of the initial bismuth (ICP-OES analysis) remaining in the aqueous layer, highlighting the possibility of controlling the waste bismuth salts.

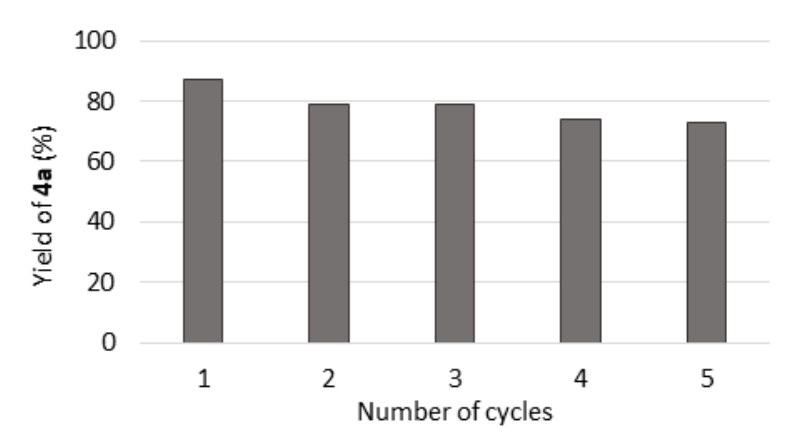

Figure 2. Recyclability of the system.

A possible mechanism for the synthesis of sulfones is depicted in Scheme 2. Firstly, $\mathrm{Na}_{2} \mathrm{~S}_{2} \mathrm{O}_{5}$ disaggregation occurs throw homolytic cleavage of the S-S bond. This step includes radical intermediates, ${ }^{[21]}$ which is in consonance with radicaltrapping experiments (Scheme 1). In this experiment, any TEMPO-derived trapping product were detected. Only the hydroxylamine or amine TEMPO derived products were detected by MS-GC while triarylbismuthine remained unchanged. These radical intermediates, suffer a disproportionation to afford solvated $\mathrm{SO}_{2}$. Then, $\mathrm{SO}_{2}$ undergoes insertion between $\mathrm{C}-\mathrm{Bi}$ bond. ${ }^{[22]}$

The excess of chlorides in deep eutectic medium, may favour the $\mathrm{BiCl}_{3}$ released, affording the corresponding sulfinate. The generation of the sulfinate intermediate could be detected monitoring the reaction by phase-reversed HPLC, as has been evidenced in a related proccess. ${ }^{[10 \mathrm{~b}]}$ Finally, sulfinate reacts with an electrophile to give the desired sulfone product.

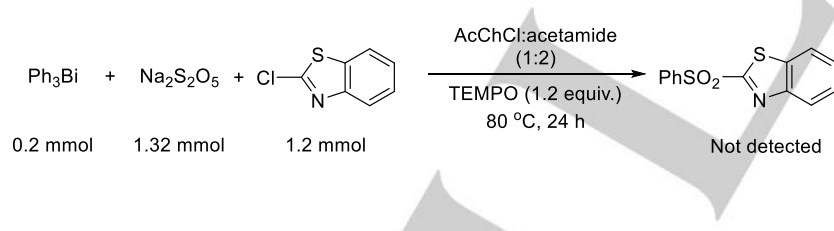

Scheme 1. Radical trapping experiment.

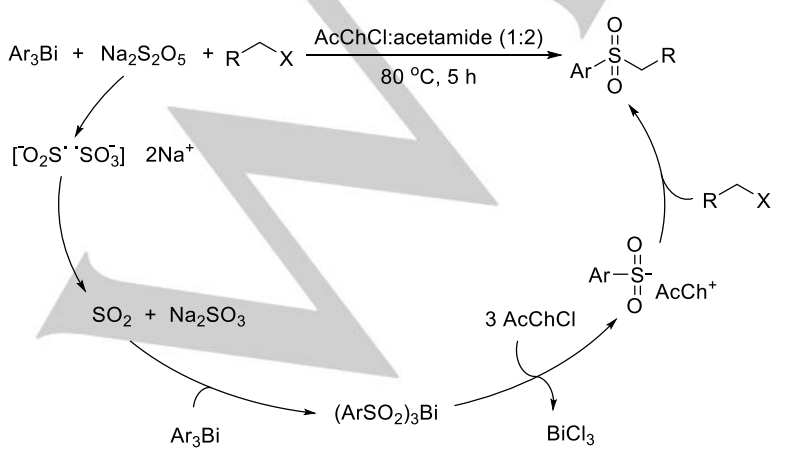

Scheme 2. Proposed mechanism for the synthesis of sulfones.

A plausible mechanism for the sulfides and disulfides synthesis is also proposed in Scheme 3. Acetamide, one of the DES components, or also other proton source from the media, such as moisture, reacts with $I_{2}$ to get hydrogen iodide. Then, the in situ generated sulfinate (see Scheme 2), reacts repeatedly with $\mathrm{HI}$ to give the corresponding hypoiodothioite, which could react with a nucleophile to afford different sulfides or suffer recombination to give symmetrical disulfides. ${ }^{[18]}$
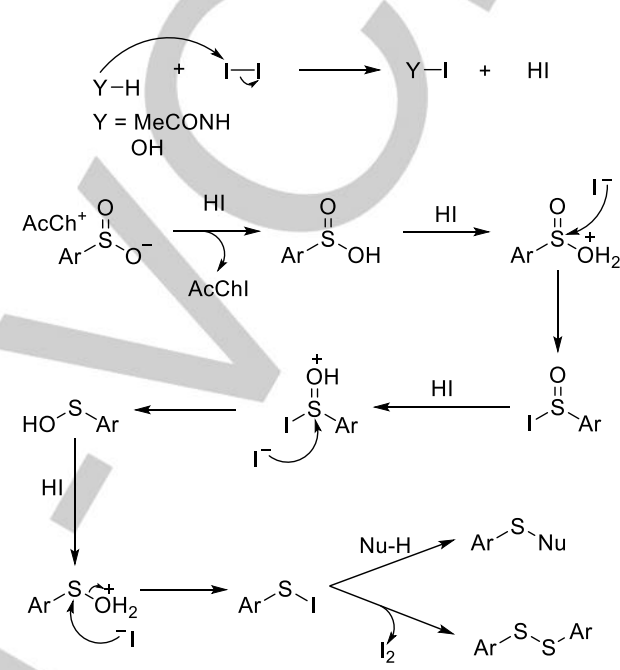

Scheme 3. Proposed mechanism for the sulfides and disulfides synthesis

\section{Conclusion}

In summary, a multicomponent synthesis of sulfones, disulfides or sulfides from triarylbismuthines and $\mathrm{Na}_{2} \mathrm{~S}_{2} \mathrm{O}_{5}$ in AcChCl:acetamide (1:2), as reaction medium, has been described for the first time. The results highlighted the importance of the choice of the adequate solvent, which enhanced the reactivity of the system and also, provides plenty of opportunities for developing new and unexplored synthetic routes. In terms of sustainability of this methodology, it is interesting to mention that i) arylboronic acids have been replaced by non-toxic aryl sources as $\mathrm{Ar}_{3} \mathrm{Bi}$, increasing the atom economy of the process $\left(\mathrm{Ar}_{3} \mathrm{Bi}\right.$ can react with 3 equivalents of an electrophile); ii) non-harmful reagent $\left(\mathrm{Na}_{2} \mathrm{~S}_{2} \mathrm{O}_{5}\right)$ has been used as $\mathrm{SO}_{2}$ source; iii) the careful choice of DES allowed a good solubility and reactivity of all reagents, allowing the recyclability of the reaction 5 consecutive cycles in a non-toxic solvent media; iv) the waste bismuth salt could be controlled adjusting the $\mathrm{pH}$ of the aqueous solution used in the work-up v) and finally, the process avoided the use of catalysts under aerobic conditions.

\section{Experimental Section}

General. Solvents and reagents were used as obtained from commercial sources and without purification. ${ }^{1} \mathrm{H}$ NMR spectra were recorded on Bruker AC-300 or AC-400 NMR spectrometers in proton coupled mode. 
${ }^{13} \mathrm{C}$ NMR spectra were recorded on Bruker AC-300 or AC-400 NMR spectrometers, in proton decoupled mode at $20^{\circ} \mathrm{C}$; chemical shifts were given in $\delta$ (parts per million) and coupling constants $(J)$ in Hertz. Lowresolution mass spectra (EI) were obtained at $70 \mathrm{eV}$ on an Agilent Technologies GC/MS-5973N spectrometer and low-resolution HPLC with electrospray ionization (HPLC-ESI) mass spectra were recorded employing an Agilent model 1100 Series, giving fragment ions in $\mathrm{m} / \mathrm{z}$ with relative intensities (\%) in parentheses. High-resolution mass spectra were obtained on an Agilent 7200 flight (Q-TOF) spectrometer. Infrared spectra were measured on a Jasco FT/IR-4100 Fourier Transform Infrared Spectometer. Melting points were obtained with a Reichert Thermovar apparatus. The chromatographic analyses (GC) were determined with a Younglin 6100 instrument equipped with a flame ionization detector and $30 \mathrm{~m} \mathrm{HP}-5$ capillary column $(0.25 \mathrm{~mm}$ diam, 0.33 $\mathrm{mm}$ film thickness), using nitrogen $(2 \mathrm{~mL} / \mathrm{min})$ as a carrier gas, $\mathrm{T}_{\text {injector }}=$ $270 \stackrel{\circ}{\circ}, T_{\text {column }}=60{ }^{\circ} \mathrm{C}(3 \mathrm{~min})$ and $60-270{ }^{\circ} \mathrm{C}(15 \stackrel{\circ}{\circ} \mathrm{C} / \mathrm{min}), \mathrm{P}=12 \mathrm{psi}$. Thin layer chromatography (TLC) was carried out on Schleicher \& Schuell F1400/LS 254 plates coated with a $0.2 \mathrm{~mm}$ layer of silica gel; detection by $U_{254}$ light. Column chromatography was performed using silica gel 60 of 40-63 mesh. UV-Vis spectra were recorded in a SHIMAZDU UV-1603 apparatus. The Inductively Coupled Plasma Optical Emission Spectroscopy (ICP-OES) analysis were performed in the units Technical Services Research at the University of Alicante with an inductively coupled plasma optical emission spectroscopy: Perkin Elmer. Optima 4300DV (Dual vision).

General synthesis of $\mathrm{Ar}_{3} \mathrm{Bi}$. For commercially available organomagnesium reagents, a solution of $\mathrm{BiCl}_{3}$ in dry THF $(2 \mathrm{mmol}, 1 \mathrm{M})$ was added dropwise over a solution of $\mathrm{ArMgBr}$ in $\mathrm{THF}$ or $\mathrm{Et}_{2} \mathrm{O}(1 \mathrm{M})$ under an argon atmosphere with magnetic stirring. Once the addition was complete, the solution was heated at reflux for $12 \mathrm{~h}$. Then, the reaction was allowed to reach room temperature and poured slowly over a cold saturated aqueous solution of $\mathrm{NH}_{4} \mathrm{Cl}$. The product was extracted 3 times with $\mathrm{Et}_{2} \mathrm{O}$. The combined organic phases were dried over $\mathrm{MgSO}_{4}$ and the solvent was removed under reduced pressure. ${ }^{[23]}$

For non-commercially available organomagnesium reagents, the corresponding aryl iodide/bromide $(6.2 \mathrm{mmol})$ was dissolved in dry THF and cooled to $-78{ }^{\circ} \mathrm{C}$ in an acetone bath. A n-BuLi solution $(2.5 \mathrm{M}, 6.2$ $\mathrm{mmol}$ ) was added dropwise and the mixture was stirred at that temperature for $1 \mathrm{~h}$. Then, a suspension of $\mathrm{BiCl}_{3}(2 \mathrm{mmol})$ in dry THF was added dropwise and the mixture was slowly allowed to reach room temperature. The corresponding mixture was stirred overnight at it and then quenched with sat. aq. $\mathrm{NaHCO}_{3}$. The aqueous layer was extracted with EtOAc $(15 \mathrm{~mL} \times 3)$ and the combined organic layers were washed with $\mathrm{H}_{2} \mathrm{O}$ and brine. The organic layer was dried over $\mathrm{MgSO}_{4}$, filtered and concentrated under reduced pressure. $\mathrm{Ar}_{3} \mathrm{Bi}$ was usually purified by recrystallization from hot EtOH or by flash chromatography using a mixture of EtOAc and hexanes. ${ }^{[24]}$

General procedure for the preparation of DESs. A mixture of hydrogen-bond donor and hydrogen-bond acceptor, with the previously specified molar ratio, was added in a round bottom flask under an inert atmosphere. The mixture was stirred for 60 minutes in a $T$ range between 65 and $80^{\circ} \mathrm{C}$ obtaining the corresponding DES.

General procedure for the synthesis of sulfones. A solution of $\mathrm{Ar}_{3} \mathrm{Bi}$ $(0.2 \mathrm{mmol})$, sodium metabisulfite $(1.32 \mathrm{mmol})$ and the corresponding electrophile $(1.2 \mathrm{mmol})$ in $1.5 \mathrm{~mL}$ of DES was stirred for $5 \mathrm{~h}$ at $80{ }^{\circ} \mathrm{C}$. Once the reaction was completed, water was added to dissolve the DES phase. The aqueous suspension was extracted with EtOAc $(5 \mathrm{~mL} \times 3)$. The combined organic layers were dried over $\mathrm{MgSO}_{4}$ and concentrated under reduced pressure. Products were usually purified by chromatography on silica gel (hexane/ethyl acetate).

General procedure for the synthesis of disulfides. A solution of $\mathrm{Ar}_{3} \mathrm{Bi}$ $(0.2 \mathrm{mmol})$, sodium metabisulfite $(1.32 \mathrm{mmol})$ in $1.5 \mathrm{~mL}$ of DES was stirred for $5 \mathrm{~h}$ at $80{ }^{\circ} \mathrm{C}$. Then, $\mathrm{I}_{2}(1.2 \mathrm{mmol})$ was added and the reaction was stirred for 20 min. Once the reaction was completed, water was added to dissolve the DES phase. The aqueous suspension was extracted with EtOAc $(5 \mathrm{~mL} \times 3)$. The combined organic layers were dried over $\mathrm{MgSO}_{4}$ and concentrated under reduced pressure. Products were usually purified by chromatography on silica gel (hexane/ethyl acetate).

General procedure for the synthesis of sulfides. A solution of $\mathrm{Ar}_{3} \mathrm{~B}$ $(0.2 \mathrm{mmol})$, sodium metabisulfite $(1.32 \mathrm{mmol})$ in $1.5 \mathrm{~mL}$ of DES was stirred for $5 \mathrm{~h}$ at $80^{\circ} \mathrm{C}$. Then, $\mathrm{I}_{2}(1.2 \mathrm{mmol})$ was added and the reaction was stirred for $20 \mathrm{~min}$, before the corresponding pro-nuclephile was added $(1.2 \mathrm{mmol})$. Once the reaction was completed, water was added to dissolve the DES phase. The aqueous suspension was extracted with EtOAc $(5 \mathrm{~mL} \times 3)$. The combined organic layers were dried over $\mathrm{MgSO}_{4}$ and concentrated under reduced pressure. Products were usually purified by chromatography on silica gel (hexane/ethyl acetate).

General Procedure for Recycling Experiments. The reaction was performed according to the general procedure. Once the reaction was completed, the reaction mixture was cooled to room temperature, and 2 MeTHF $(3 \mathrm{~mL} \times 3)$ was added to the reaction vessel. The biphasic mixture was stirred for $5 \mathrm{~min}$, and the upper phase (VOC-phase, mainly unreacted organic reagents and products) was separated by decantation and analyzed by GC using tridecane as the internal standard. The eutectic mixture was dried under vacuum and was charged again with fresh reagents, repeating the process.

\section{Acknowledgements}

This work was supported by the University of Alicante (VIGROB$316 \mathrm{FI}$ ) and the Spanish Ministerio de Economia, Industria y Competitividad (PGC2018-096616-B-100). BS and XM thanks Generalitat Valenciana (ACIF/2017/211 and ACIF/2016/057, respectively) for their fellowships.

\section{Keywords: Bismuth • Multicomponent reactions • Solvent} effects $\cdot$ Sulfur $\cdot$ Sustainable chemistry

[1] a) N. S. Simpkins, Sulphones in organic synthesis, Pergamon, Oxford New York, 1993; b) A. El-Awa, M. N. Noshi, X. M. du Jourdin, P. L. Fuchs, Chem. Rev. 2009, 109, 2315-2349; c) B. M. Trost, C. A. Kalnmals, Chem. Eur. J. 2019, 25, 11193-11213.

[2] a) C. Y. Meyers, A. M. Malte, W. S. Matthews, J. Am. Chem. Soc. 1969 91, 7510-7512; b) S. C. Söderman, A. L. Schwan, J. Org. Chem. 2012 77, 10978-10984.

[3] C. Aïssa, Eur. J. Org. Chem. 2009, 2009, 1831-1844.

[4] a) P. Devendar, G.-F. Yang, Top. Curr. Chem. 2017, 375, 1-44; b) K. A Scott, J. T. Njardarson, Top. Curr. Chem. 2018, 376, 1-34; c) C. Zhao, K. P. Rakesh, L. Ravidar, W.-Y. Fang, H.-L. Qin, Eur. J. Med. Chem. 2019, 162, 679-734.

[5] S. Matavos-Aramyan, S. Soukhakian, M. H. Jazebizadeh, Phosphorus, Sulfur Silicon Relat. Elem. 2019.

[6] a) S. Cacchi, G. Fabrizi, A. Goggiamani, L. M. Parisi, Org. Lett. 2002, 4 4719-4721; b) B. Bandgar, S. V. Bettigeri, J. Phopase, Org. Lett. 2004 6, 2105-2108; c) A. Kar, I. A. Sayyed, W. F. Lo, H. M. Kaiser, M. Beller M. K. Tse, Org. Lett. 2007, 9, 3405-3408; d) N.-W. Liu, S. Liang, G. Manolikakes, Synthesis 2016, 48, 1939-1973; e) N. W. Liu, S. Liang, N. Margraf, S. Shaaban, V. Luciano, M. Drost, G. Manolikakes, Eur. J. Org. Chem. 2018, 2018, 1208-1210; f) J. Liu, L. Zheng, Adv. Synth. Catal. 2019, 361, 1710-1732.

[7] J. Zhu, W.-C. Yang, X.-d. Wang, L. Wu, Adv. Synth. Catal. 2018, 360, 386-400.

[8] A. S. Deeming, E. J. Emmett, C. S. Richards-Taylor, M. C. Willis, Synthesis 2014, 46, 2701-2710. 
[9] E. J. Emmett, M. C. Willis, Asian J. Org. Chem. 2015, 4, 602-611.

[10] a) S. Ye, G. Qiu, J. Wu, Chem. Commun. 2019, 55, 1013-1019; b) X. Marset, G. Guillena, D. J. Ramón, Chem. Eur. J. 2017, 23, $10522-$ 10526.

[11] a) D. A. Alonso, A. Baeza, R. Chinchilla, G. Guillena, I. M. Pastor, D. J. Ramón, Eur. J. Org. Chem. 2016, 612-632; b) D. J. Ramón, G. Guillena Deep Eutectic Solvents: Synthesis, Properties, and Applications, WileyVCH: Weinheim, 2019

[12] G. Dilauro, L. Cicco, F. M. Perna, P. Vitale, V. Capriati, C. R. Chimie 2017, 20, 617-623.

[13] P. T. Anastas, J. C. Warner, Green Chemistry: Theory and Practice, Oxford University Press, Oxford, 1998.

[14] X. Marset, J. Torregrosa-Crespo, R. M. Martínez-Espinosa, G. Guillena, D. J. Ramón, Green Chem. 2019, 21, 4127-4132.

[15] D. Yang, M. Hou, H. Ning, J. Zhang, J. Ma, G. Yang, B. Han, Green Chem. 2013, 15, 2261-2265.

[16] H. Suzuki, Y. Matano, Organobismuth chemistry, Elsevier, Amsterdam, 2001.

[17] J. Torregrosa-Crespo, X. Marset, G. Guillena, D. J. Ramón, R. María Martínez-Espinosa, Sci. Total Environ. 2020, 704, 135382.

[18] O. Shigeru, T. Hideo, Bull. Chem. Soc. Jpn. 1983, 56, 3813-3817.

[19] a) D. Wang, R. Zhang, S. Lin, Z. Yan, S. Guo, RSC Adv. 2015, 5, 108030-108033; b) Y. Gao, Y. Gao, X. Tang, J. Peng, M. Hu, W. Wu, H. Jiang, Org. Lett. 2016, 18, 1158-1161; c) F. Xiao, S. Chen, J. Tian, H. Huang, Y. Liu, G.-J. Deng, Green Chem. 2016, 18, 1538-1546.

[20] D. Prat, O. Pardigon, H.-W. Flemming, S. Letestu, V. Ducandas, P. Isnard, E. Guntrum, T. Senac, S. Ruisseau, P. Cruciani, P. Hosek, Org Process Res. Dev. 2013, 17, 1517-1525.

[21] E. G. Janzen, J. Phys. Chem. 1972, 76, 157-162.

[22] B. C. Smith, C. B. Waller, J. Organomet. Chem. 1971, 32, C11-C12.

[23] H. El Ghaoui, M. Raihane, B. Rhouta, N. Bitinis, A. Carlmark, M. Arroyo, R. Verdejo, M. A. Lopez-Manchado, M. Lahcini, Polym. Int. 2014, 63 709-717.

[24] a) J. Luan, L. Zhang, Z. Hu, Molecules 2011, 16, 4191-4230; b) J.-Q. Liu, J.-J. Yang, J.-F. Li, K. Li, X.-D. Xiao, Y.-L. Bai, J.-W. Wang, Mol. Catal. 2017, 443, 125-130. 


\section{Entry for the Table of Contents}

Insert graphic for Table of Contents here.

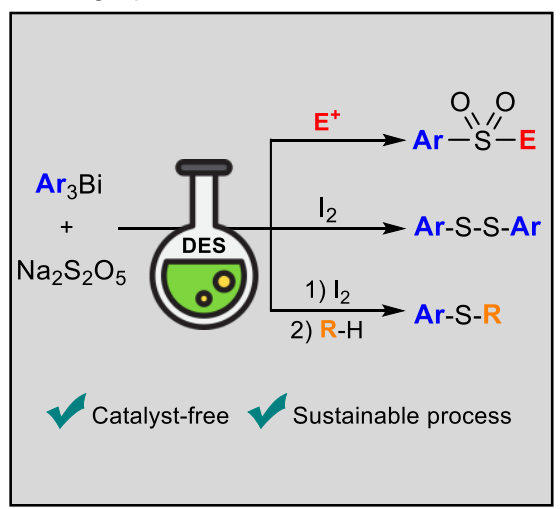

Key Topic: Deep Eutectic Solvents. Efficient multicomponent synthesis of sulfones, disulfides and sulfides from triarylbismuthines and $\mathrm{Na}_{2} \mathrm{~S}_{2} \mathrm{O}_{5}$ in Deep Eutectic Solvents (DESs), has been described for the first time. 